\title{
EL OUTSOURCING, SUS EFECTOS EN LA REDUCCIÓN DE COSTOS Y EL INCREMENTO DEL VALOR
}

José Manuel Ballester Fernández

Director de Masters en la empresa Oesía

España

\section{Resumen}

El acelerado mundo actual y su creciente complejidad imponen a las organizaciones nuevos retos que afectan su supervivencia, para lo cual los avances tecnológicos ofrecen innegables ventajas a través del ahorro de costes. Sin embargo, su aplicación genera numerosos problemas, pues, a diferencia de lo que sus fabricantes preconizan sobre la facilidad de su utilización, adecuarse a estas tecnologías demanda procesos de aprendizaje de las personas encargadas que ralentizan su efectividad. Frente a esta situación, a las organizaciones les resulta más rentable la externalización —offshore outsourcing - de ciertos servicios o procesos de negocio.

Palabras clave:

Outsourcing, gestión de las TIC (tecnologías de la información y las comunicaciones) externalizadas, consultoría de sistemas, reducción de costes en TIC, gestión de la seguridad, gobierno de tecnologías de la información. 


\section{Expansión del outsorcing}

Un estudio reciente de Forrester rectifica y eleva al 40\% la previsión de crecimiento del offshore outsourcing, indicando que la cifra continuará incrementándose, combinando las funciones de gestión de procesos con las TIC, hasta deslocalizar, lo que significa que las organizaciones trasladarán las operaciones y los procesos a otros países para ahorrar alrededor de 3,4 millones de los puestos de trabajo denominados de "cuello blanco" antes del 2015. Si se profundiza el análisis en términos salariales, un estudio de la consultora especializada Hewitt Associates indica que, debido al incremento de la demanda de outsourcing procedente de otros países - por ejemplo India o China-, los precios de estos servicios subirán alrededor del 15\% en el próximo ejercicio. Por esta razón, algunas compañías, como General Electric, que emplea a más de 12.000 profesionales de las TIC en todo el mundo a través de empresas subcontratistas, están deslocalizando sus centros de trabajo TIC hacia estos países.

Frente a esta expansión se encuentra la respuesta de los usuarios. El estudio realizado por quinto año consecutivo por Proudfoot Consulting en varios países -Alemania, Austria, España, Francia, Hungría, Portugal, Reino Unido, Estados Unidos y Australia- demuestra el grado de satisfacción de las empresas que contratan el servicio. La encuesta a 816 altos ejecutivos de grandes organizaciones señala que solo el $42 \%$ ha obtenido lo que esperaba respecto a la reducción de costes. En el caso de España, el 52\% de los directivos que subcontrataron el outsourcing afirma que sus expectativas se han visto defraudadas.

Respecto a la deslocalización, más de las tres cuartas partes de los ejecutivos españoles encuestados por Proudfoot declararon que todavía no han reubicado ninguna función de sus organizaciones, aunque se trata de una práctica que está comenzando a implantarse. Aún así, los ejecutivos españoles creen que tanto el outsourcing como la deslocalización reducirán sus costes. La mayoría de los directivos afirma que esperan conseguir una reducción de costes entre el $50 \%$ y el $75 \%$ conjugando ambas prácticas.

Según Proudfoot, esta reducción de costes puede ser considerable, aunque no en la magnitud en que muchos directivos esperan. En la mayoría de los casos puede alcanzarse un ahorro del 30\% ó 40\% procedente, fundamentalmente, de los menores costes de la mano de obra de los países de localización, como Marruecos, países del este de Europa, China o India. Sin embargo, a pesar del gran atractivo que tienen estos salarios bajos, un notable número de proyectos de deslocalización fallan, por la dificultad de analizar y evaluar los costes. 


\section{Outsourcing de la gestión de seguridad}

Una tendencia que cobra relevancia en la actualidad es la externalización de la gestión de seguridad (Managed Security Service, MSS). Existen muchas organizaciones que ofrecen esta alternativa como una estrategia para la obtención de un modelo costo-valor eficiente, permitiendo además reducir la ocurrencia de brechas de seguridad y optimizar las gestiones de la monitorización sobre los activos TIC de las organizaciones. Si bien el MSS es una alternativa atractiva, externalizar estos servicios requiere un conocimiento profundo acerca de las características del servicio y de los riesgos inherentes a los que se expone la empresa al delegar a un tercero la gestión de la seguridad de sus activos TIC.

Los principales servicios externalizados en un MSS pueden ser clasificados en dos grandes categorías:

- Administración de la seguridad y mantenimiento de equipos y tecnología, como es el caso de la administración y configuración de Firewall, de redes VPN (Virtual Private Network), de servicios Antivirus y Antispam e IDS (Intruder Detection System).

- Monitorización de seguridad, que consiste en el análisis detectivo de los eventos registrados (logs) por los sistemas y de los estados de los componentes, para identificar situaciones irregulares y llevar a cabo las acciones correctivas predefinidas.

Los servicios de MSS son los de mayor crecimiento en el segmento de las TIC, con un crecimiento interanual de $35 \%$. Al realizar un estudio comparativo entre una externalización y el establecimiento de estructuras internas, compuesto por expertos en seguridad y con herramientas sofisticadas, la balanza se inclina hacia la externalización. Como ejemplo, se estima que un proveedor de MSS en el mercado de Estados Unidos puede ofrecer un servicio de gestión de la seguridad TIC por el 31\% del coste que representaría a la organización la creación de una estructura completa de CISO (Chief Information Security Office). Estas diferencias se están incrementando como consecuencia de la alta demanda de expertos en seguridad TIC, haciendo de este tipo de outsourcing un contrato beneficioso en términos económicos.

Cuando se realiza un acuerdo de servicio para un MSS las organizaciones necesitan considerar con mayor detenimiento los niveles de confianza que están depositando en los subcontratistas externos y la dependencia que está creando en sus operaciones y en la propiedad de los activos TIC. El riesgo evidente es el acceso de los subcontratistas exter- 
nos a la información sensible del negocio, a los detalles técnicos y estratégicos de sus operaciones y a sus vulnerabilidades. A pesar de la firma de contratos de confidencialidad, no existe la seguridad de evitar la divulgación accidental o intencionada de esta información, hecho que puede afectar significativamente las operaciones del negocio.

Otro aspecto que se debe considerar en relación con los riesgos es si el MSS utiliza recursos compartidos o emplea plataformas exclusivas: compartir un enlace de datos o un servidor entre múltiples clientes incrementa el riesgo de que un cliente pueda acceder a la información de otro. Las empresas mejor preparadas para un MSS son aquellas que han logrado la madurez en su gestión de seguridad TIC, pues poseen un conocimiento efectivo de sus necesidades y sus riesgos. Esto las capacita para una negociación efectiva con sus subcontratistas externos.

\section{Consideraciones y conclusiones}

Iniciar un acuerdo de MSS es un proceso complejo para la transición de personas, adaptación de los procesos, cesión o adquisición de hardware y software y el establecimiento de índices e indicadores para determinar el cumplimiento de los servicios acordados y sobre el cumplimiento de las políticas de seguridad establecidas por la organización, así como el cumplimiento de las mejores prácticas y estándares en el gobierno de las TIC.

Estos elementos quedan explícitamente referidos en los acuerdos de servicio y serán monitoreados y auditados de manera regular para prevenir su incumplimiento. Uno de los aspectos que deben ser considerados son los procedimientos que se van a seguir y la propiedad intelectual de los activos, una vez concluida la relación comercial, en función de asegurar la no dependencia de un proveedor y facilitar la transición.

Un factor común a todo este ciclo (reducción de costes, externalización y creación de valor) es la seguridad. La reducción de costes no implica necesariamente una merma en la seguridad. Para obtener una efectiva reducción de los costes, es necesario determinar las tareas redundantes y superfluas que se pueden eliminar. En la fase de externalización, los contratos, y sus cláusulas y condiciones, son el elemento más relevante; de ellos depende la efectividad del ciclo. Para concluir, la creación de valor se obtiene como resultado de las fases anteriores y redundan en una mayor satisfacción de los agentes externos e internos, logrando una mayor confianza. 


\section{Referencias}

Hewitt Associates. "Outsourcing Grows Up - Strategic Management Tools" [en línea]. <http://www.hewittassociates.com/Intl/EU/enEU/Our Services/ Outsourcing/ Default.aspx>.

Gartner Group. <http://www.gartner.com/it/page.jsp?id=511956>. 